\title{
Polyimides Bearing Long-Chain Alkyl Groups and Their Application for Liquid Crystal Alignment Layer and Printed Electronics
}

\author{
Yusuke Tsuda \\ Kurume National College of Technology \\ Japan
}

\section{Introduction}

Polyimides exhibit excellent thermal and mechanical properties, and have extensive engineering and microelectronics applications. Aromatic polyimides such as polyimides based on pyromellitic dianhydride are prepared from aromatic diamines and aromatic tetracarboxylic dianhydrides via poly(amic acid)s. Since conventional aromatic polyimides are insoluble, these polymers are usually processed as the corresponding soluble poly(amic acid) precursors, and then either thermally or chemically imidized. However, owing to the instability of poly(amic acid)s and the liberation of water in the imidization process, problems can arise (Fig. 1). Extensive research has been carried out to improve the solubility of polyimides and successful recent examples involve the incorporation of fluorine moieties, isomeric moieties, methylene units, triaryl imidazole pendant groups, spiro linkage groups, and sulfonated structure. Soluble polyimides bearing long-chain alkyl groups have also been reported, and their applications mainly involve their use as alignment layers for liquid crystal displays (LCDs).

Our research group has systematically investigated the synthesis and characterization of soluble polyimides based on aromatic diamines bearing long-chain alkyl groups such as alkyldiaminobenzophenone (ADBP-X, $\mathrm{X}=$ carbon numbers of alkyl chain) (Tsuda et al., 2000a) alkoxydiaminobenzene (AODB-X) (Tsuda et al., 2000b), diaminobenzoic acid alkylester (DBAE-X) (Tsuda et al., 2006), and alkyldiaminobenzamide (ADBA-X) (Tsuda et al., 2008), and the results from these research are described in the original papers and the review paper (Tsuda, 2009). Our recent paper has described soluble polyimides having dendritic moieties on their side chain, and it was found that these polyimides having dendritic side chains were applicable for the vertically aligned nematic liquid crystal displays (VAN-LCDs) (Tsuda et al., 2009). These dendronized polyimides were synthesized using the novel diamine monomer having a first-generation monodendron, 3,4,5-tris(ndodecyloxy)benzoate and the monomer having a second-generation monodendron, 3,4,5tris[-3', $4^{\prime}, 5^{\prime}$-tri(n-dodecyloxy)benzyloxy] benzoate.

Some soluble polyimides were synthesized from the diamine monomer having three longchain alkyl groups; aliphatic tetracarboxylic dianhydride; 5-(2,5-dioxotetrahydrofuryl)-3methyl-3-cyclohexene-1,2-dicarboxylic anhydride (Cyclohexene-DA) or aromatic tetracarboxylic dianhydride; 3,3',4,4'-diphenylsulfone tetracarboxylic dianhydride (DSDA) 


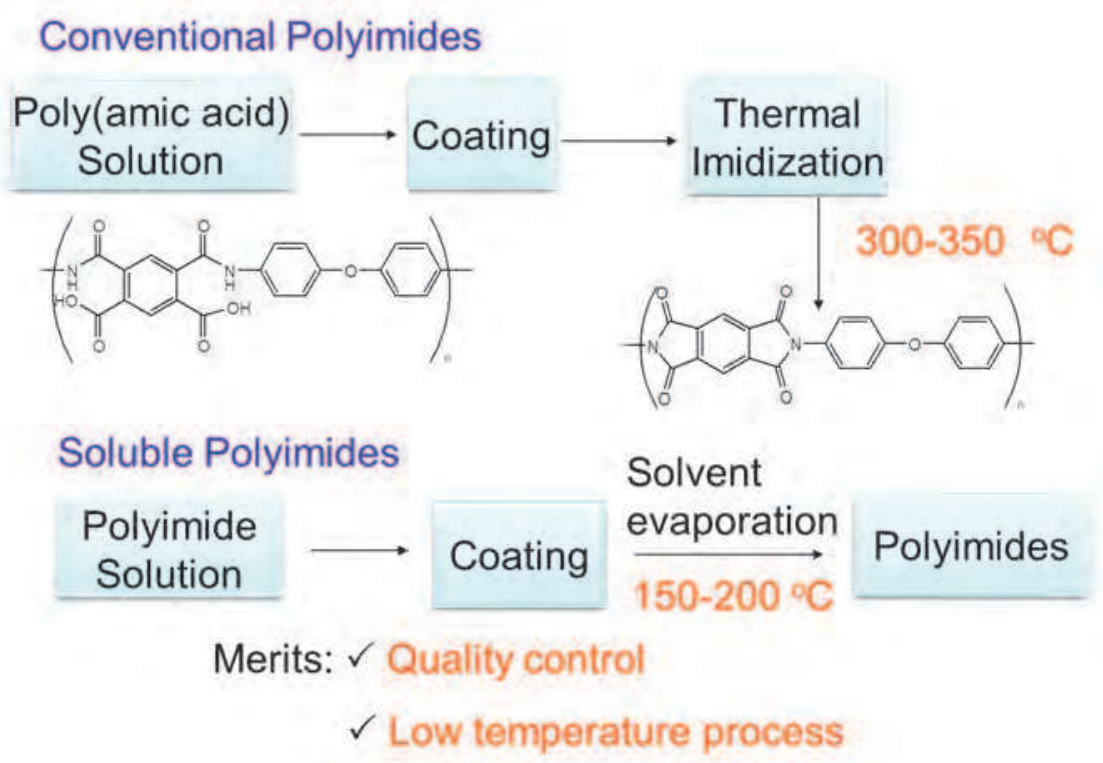

Fig. 1. Conventional polyimides and soluble polyimides

or 3,4'-oxydiphthalic anhydride $\left(3,4^{\prime}\right.$-ODPA) as a dianhydride, and 4,4'diaminodiphenylether (DDE) as a diamine co-monomer. Thin films of the obtained polyimides were irradiated by UV light $(\lambda \max ; 254 \mathrm{~nm})$, and the contact angles for the water decreased from near $100^{\circ}$ (hydrophobicity) to near $20^{\circ}$ (hydrophilicity) in proportion to the irradiated UV light energy. Thus, the surface wettability of polyimides bearing longchain alkyl groups can be controlled by UV light irradiation, such methods are expected to be applied in the field of organic, flexible and printed electronics (Tsuda et al., 2010, 2011a, 2011b).

In this chapter, the author reviews the synthesis and basic properties of soluble polyimides bearing long-chain alkyl groups, and their application for liquid crystal alignment layer and printed electronics.

\section{Results and discussion}

In this section, the synthesis of aromatic diamine monomers having long-chain alkyl groups and corresponding soluble polyimides bearing long-chain alkyl group (Fig. 2), their basic polymer properties, and the application for VAN-LCDs and printed electronics are described.

\subsection{Synthesis of aromatic diamine monomers containing long-chain alkyl groups}

The synthesis routes for aromatic diamines bearing single long-chain alkyl groups are illustrated in Fig. 3. Alkyldiaminobenzophenones (ADBP-9 14) were prepared via two steps using 3,5-dinitrobenzoyl chloride as the starting material. The Friedel-Crafts reaction of 3,5dinitrobenzoyl chloride with alkylbenzene catalyzed by aluminum chloride in nitrobenzene gave 3,5-dinitro- $4^{\prime}$-alkylbenzophenones in good yields. The reduction of 3,5-dinitro- $4^{\prime}-$ 


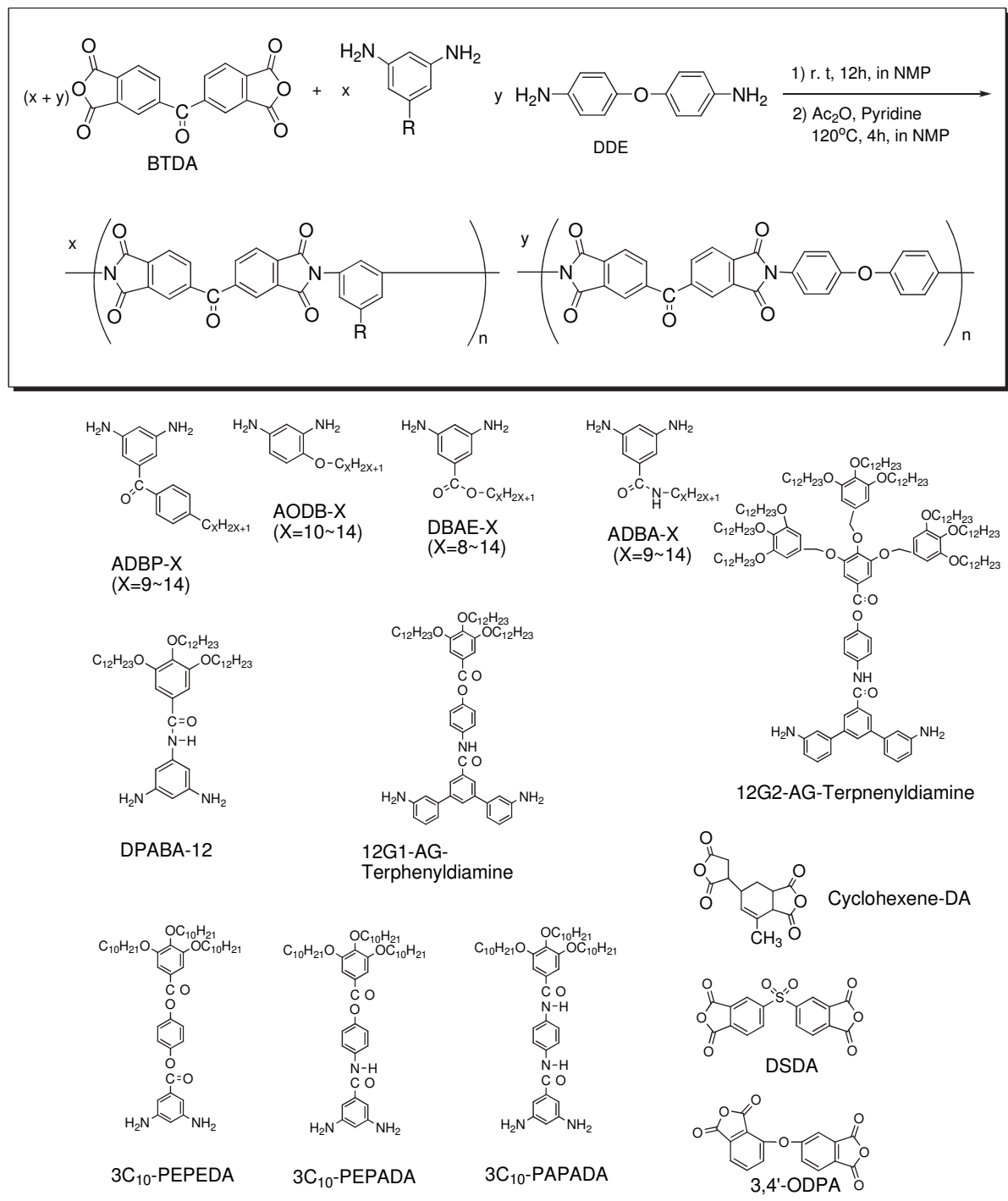

Fig. 2. Soluble polyimides bearing long-chain alkyl groups

alkylbenzophenone was performed by catalytic hydrogenation using palladium on carbon and hydrogen gas introduced by 3-5 L gas-bag. Although hydrazine hydrate/ethanol system is sometimes used for the reduction of nitro compounds, this system is not preferred because the carbonyl group in 3,5-dinitro-4'-alkylbenzophenones reacts with hydrazine.

Alkyloxydiaminobenzenes (AODB-10 14) were prepared in two steps using 2,4dinitrophenol as the starting material. The Williamson reaction using 2,4-dinitrophenol and 1-bromoalkanes catalyzed by potassium carbonate in DMAc gave 1-alkyloxy-2,4dinitrobenzenes in satisfactory yields. The reduction of 1-alkyloxy-2,4-dinitrobenzenes was performed by catalytic hydrogenation using $\mathrm{Pd} / \mathrm{C}$ and hydrogen gas at 0.2-0.3 Mpa. 

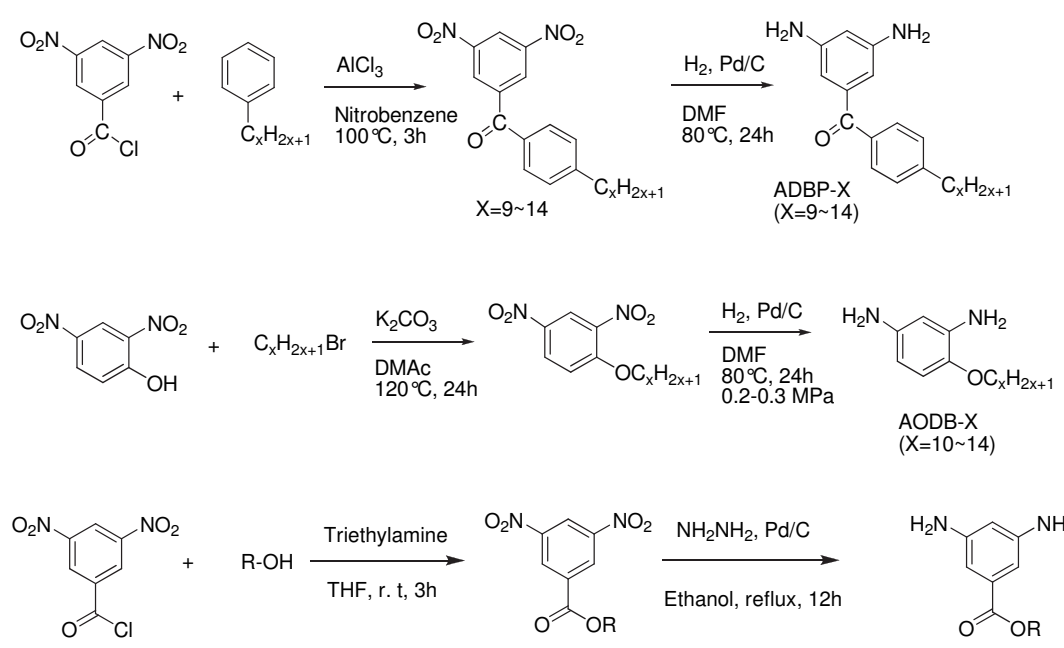

$$
\text { DBAE-8 14 }\left(\mathrm{R}=\mathrm{n}-\mathrm{C}_{8} \mathrm{H}_{17} \sim \mathrm{n}-\mathrm{C}_{14} \mathrm{H}_{29}\right) \quad \text { DBAE-9-branch-B }
$$
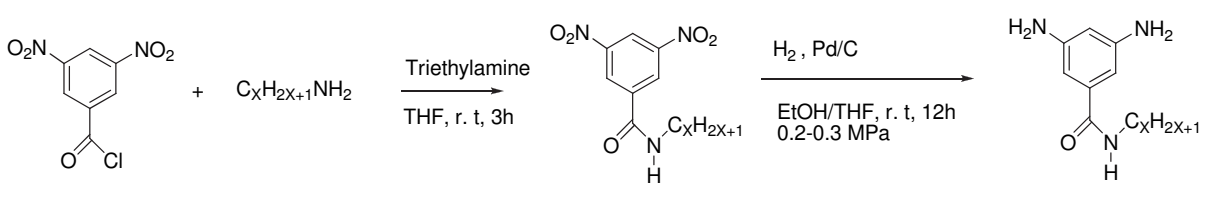

ADBA- $X(X=9 \sim 14)$

Fig. 3. Synthesis of aromatic diamines having single long-chain alkyl groups

Although the hydrazine hydrate/ethanol system can be used for the reduction of nitrocompounds, the medium pressure system is preferable due to better yields and purity of the products.

Diaminobenzoic acid alkylesters (DBAE-8 14) were prepared in two steps using 3,5dinitrobenzoyl chloride as the starting material. The esterification reaction using 3,5dinitrobenzoyl chloride and aliphatic alcohols having long-chain alkyl groups catalyzed by triethylamine in THF gave alkyl 3,5-dinitrobenzoate in satisfactory yield. The reduction of alkyl 3,5-dinitrobenzoate was performed by catalytic hydrogenation using $\mathrm{Pd} / \mathrm{C}$ as a catalyst and hydrazine hydrate/ethanol as a hydrogen generator. The relatively mild hydrogenation using hydrazine hydrate/ethanol system seemed to be preferable in the case of alkyl 3,5dinitrobenzoate, because the scissions of ester linkages were sometimes recognized besides the hydrogenation of nitro-groups in the use of medium pressure hydrogenerator.

Alkyldiaminobenzamides (ADBA-9 14) were prepared in two steps using 3,5dinitrobenzoyl chloride as the starting material. The condensation reaction using 3,5dinitrobenzoyl chloride and aliphatic amines having long-chain alkyl groups catalyzed by triethylamine in THF gave $\mathrm{N}$-alkyl-3,5-diaminobenzamides in satisfactory yields. The reduction of $\mathrm{N}$-alkyl-3,5-diaminobenzamide was performed by catalytic hydrogenation using $\mathrm{Pd} / \mathrm{C}$ and hydrogen gas at $0.2-0.3 \mathrm{MPa}$ in a medium pressure hydrogenerator in satisfactory yield $(60-80 \%)$.

The aromatic diamines containing first-generation dendritic moieties, N-(3,5diaminophenyl)-3,4,5-tris(alkoxy)benzamide (DPABA-X, X=6,12), were synthesized 

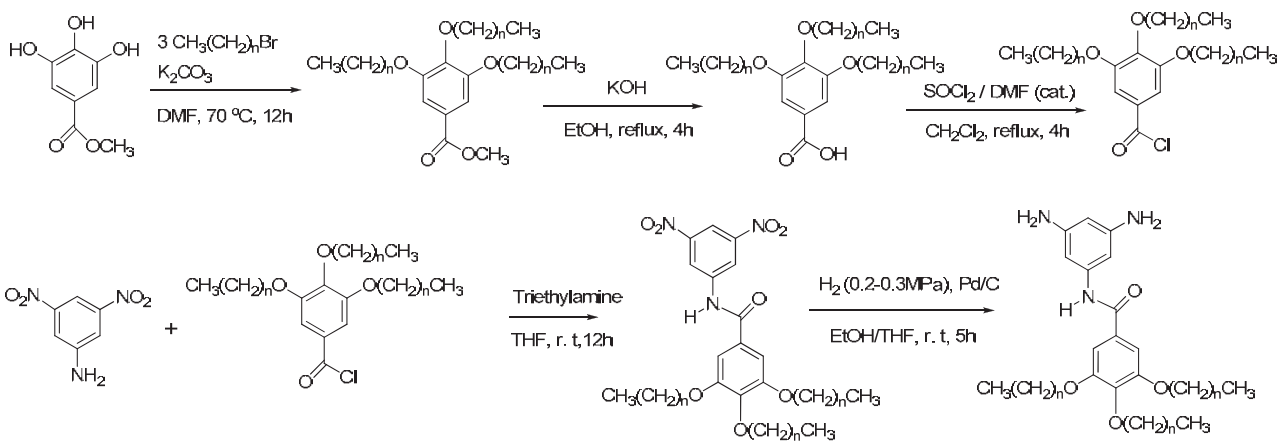

DPABA-6; $n=5$ DPABA-12; $\mathrm{n}=11$

Fig. 4. Synthesis of aromatic diamines having triple long-chain alkyl groups

following the method shown in Fig. 4. 3,4,5-Trialkyloxybenzoyl chloride, known as the building block for Percec-type dendrons, was synthesized from 3,4,5-trihydroxybenzoic acid methyl ester (gallic acid methyl ester) followed by Williamson-etherification using alkylbromide catalyzed by potassium carbonate, hydrolysis of ester groups by potassium hydroxide, then acid chlorination using thionyl chloride. The condensation reaction using the above acid chloride and 3,5-dinitroaniline catalyzed by triethylamine gave the dinitroprecursor of DPABA, and this was finally hydrogenated to DPABA.

4-[3,5-Bis(3-aminophenyl)phenyl]carbonylamino]phenyl 3,4,5-tris (n-dodecyloxy)benzyloxy benzoate (12G1-AG-Terphenyldiamine) and 4-[3,5-Bis (3-aminophenyl) phenyl] carbonylamino] phenyl 3,4,5-tris[3', 4', 5'-tris(n-dodecyloxy) benzyloxy] benzoate (12G2-AGTerphenyl diamine) were synthesized by the method shown in Fig. 5 using the first- and second- generation Percec-type monodendrons. These synthesis routes include the condensation reactions with 3,5-dibromo benzoic acid and 3',4',5'-tris (ndodecyloxy)benzyloxy chloride with 4-aminophenol, followed by Suzuki coupling reaction with 3-aminophenyl boronic acid. It is considered that these synthetic methods of aromatic diamine monomers using Suzuki coupling are the versatile method as the synthesis of aromatic diamines without the severe reduction that sometime causes the side reaction.

Novel diamine monomers, such as $3 \mathrm{C}_{10}$-PEPEDA, $3 \mathrm{C}_{10}$-PEPADA and $3 \mathrm{C}_{10}$-PAPADA having three long-chain alkyl groups connected by phenylester and/or phenylamide linkages were recently synthesized via several step reactions from Gallic acid methyl ester using protect group synthetic technique. The detail description of these monomer syntheses will be reported elsewhere.

\subsection{Synthesis of soluble polyimides bearing long-chain alkyl groups}

The synthesis route for the polyimides and copolyimides based on BTDA (Cyclohexene-DA, DSDA, 3,4'-ODPA), DDE and aromatic diamines bearing long-chain alkyl groups is illustrated in Fig. 2. Two-step polymerization systems consisting of poly(amic acid)s synthesis and chemical imidization were performed. The poly(amic acid)s were obtained by reacting the mixture of diamines with an equimolar amount of BTDA at room temperature for $12 \mathrm{~h}$ under an argon atmosphere. Polyimides were obtained by chemical imidization at $120^{\circ} \mathrm{C}$ in the presence of pyridine as base catalyst and acetic anhydride as dehydrating agent. These are the optimized synthesis conditions previously developed for the synthesis 


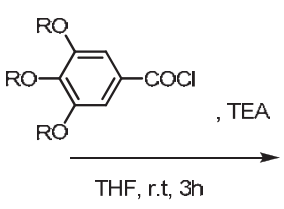<smiles>[R]Oc1cc(C(=O)Oc2ccc(NCC)cc2)cc(O)c1O</smiles>

DME, $80^{\circ} \mathrm{C}, 24 h$

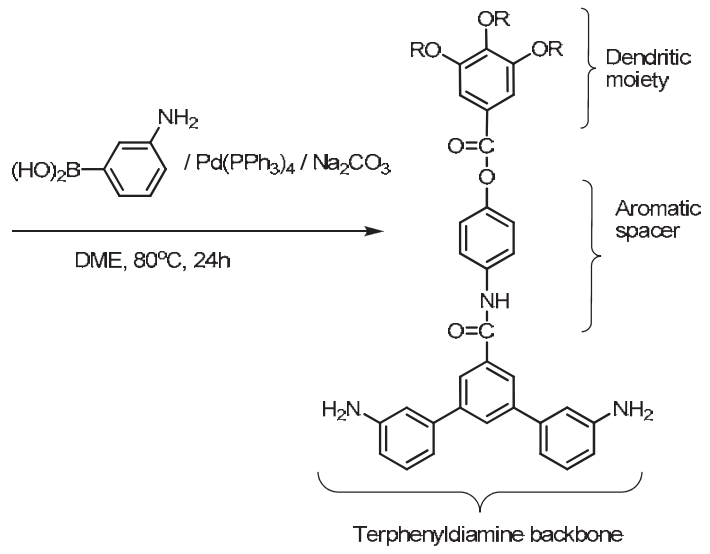<smiles>O=C(Nc1ccc(O)cc1)c1cc(Br)cc(Br)c1</smiles>

12G2-AG-Terphenyldiamine $(\mathrm{R}=\mathrm{CH}_{2} \underbrace{-\mathrm{OCH}_{2} \mathrm{CH}_{2} \mathrm{CH}_{2}\left(\mathrm{CH}_{2}\right)_{8} \mathrm{CH}_{3}}_{\mathrm{OCH}_{2} \mathrm{CH}_{2} \mathrm{CH}_{2}\left(\mathrm{CH}_{2}\right)_{8} \mathrm{CH}_{3}})$

Fig. 5. Synthesis of aromatic diamines having multiple long-chain alkyl groups (dendritic terphenyl diamines)

of soluble polyimides in our laboratory. BTDA, DSDA and 3,4'-ODPA, these are highly reactive and common aromatic tetracarboxylic dianhydrides were mainly used as a dianhydrides monomer, and DDE that is highly reactive and a common aromatic diamine was used as a diamine co-monomer. In the case of soluble polyimides, clear polyimide solutions were eventually obtained. In other cases, clear poly(amic acid) solutions were obtained, however, gelation or precipitation occurred in the course of imidization process. The polymerizations based on the dendritic diamine monomers, 12G1-AGterphenyldiamine and 12G2-AG-terphenyldiamine were firstly investigated using NMP as a solvent. Although viscous poly(amic acid)s solution were obtained, precipitation sometime occurred during the imidization process. It was speculated that the hydrocarbon and phenyl moiety of dendritic diamine monomers reduces the solubility of polyimides in NMP; therefore, a polar aromatic solvent, $m$-cresol or pyridine were sometime used to improve the solubility of dendritic moieties.

\subsection{Properties of soluble polyimides bearing long-chain alkyl groups}

From the continuous investigation in our laboratory, various precious data was obtained. The representative results are shown in this section. 


\subsubsection{Solubility}

As far as the solublity of polyimides based on long-chain alkyl groups is concerned, the following interesting results have been obtained. Experimental results of homopolymerization and copolymerization based on BTDA/ADBP-12, AODB-12, DBAE-12, ADBA-12, DPABA-12/DDE are summarized in Table 1. Although all polyamic(acid)s were soluble in NMP which is a solvent used for polymerization, however, the solubility of homopolyimides and copolyimides depended on polymer structures. BTDA/ADBP-12 homopolyimides and BTDA/ADBP-12/DDE copolyimides containing $40 \mathrm{~mol} \%$ of ADBP or more were soluble in NMP. Thus, the effect of long-chain alkyl group in ADBP for the enhancement of solubility was confirmed. BTDA/AODB-12 homopolyimides and BTDA/AODB-12/DDE copolyimides containing $25 \mathrm{~mol} \%$ or more of AODB-12 units were also soluble in NMP. Judging from the results of copolymerization based on BTDA/ADBP9 14/DDE and BTDA/AODB-10 14/DDE, it is recognized that AODB bearing alkyl groups via an ether linkage were more effective for the enhancement of solubility in comparison to ADBP.

On the other hand, all homopolyimides and copolyimide based on BTDA/DBAE8 14/DDE were insoluble in NMP probably due to the rigid ester linkage groups. The experimental results of copolymerization based on BTDA/ADBA-12/DDE are quite unique. Although BTDA/ADBA-12 homopolyimide was insoluble, the copolymers, BTDA/ADBA12/DDE (100/75/25) and BTDA/ADBA-12/DDE (100/50/50) were soluble in NMP. The solubility of these copolyimides may be improved by the randomizing effect based on copolymerization as well as the entropy effect of long chain linear alkyl groups. Based on the fact that all copolyimides BTDA/DBAE-8 14/DDE were insoluble in NMP, ADBA is more effective for the enhancement of solubility in comparison to DBAE. Fig. 6 summarizes the effect of functional diamines, AODB- $X$, ADBP-X, ADBA- $X$ and DBAE- $X$ bearing longchain alkyl groups for the enhancement of solubility investigated in our laboratory, and it is concluded that the effect of functional diamines are increased as AODB (ether linkage) > ADBP (benzoyl linkage) > ADBA (amide linkage) > DBAE (ester linkage) (Fig. 6). The polyimides and copolyimides based on BTDA, DPABA-6 or DPABA-12, and DDE containing $50 \mathrm{~mol} \%$ or more DPABA were soluble, showing that the effect of DPABA for the enhancement of solubility was larger than ADBA. It is speculated that the three longchain alkyl groups in DPABA enhance the solubility of polyimides.

Furthermore, several important results concerning on the structure-solubility relationships of the polyimides bearing long-chain alkyl groups are obtained and concluded as follows: (1) ADBP with an even number of carbon atoms were effective in enhancing the solubility, while polymers based on ADBP with an odd number of carbon atoms remained insoluble. It can be assumed that the conformation around C-C bonds of the long-chain alkyl groups and alignment of benzene ring attached with these alkyl groups and carbonyl group affect this odd-even effect. (2) Copolymerization using the conventional aromatic diamine, DDE resulted in the improvement of both the molecular weight and the thermal stability. (3) The copolymerization study based on AODB-10 14 and DDE demonstrated that AODB-12 having 12 methylene units was the most effective in enhancing the solubility. (5) DBAE having branched alkyl chains such as nonan-5-yl 3,5-diaminobenzoate (DBAE-9-branch-A) and 2,6-dimethylheptane-4-yl 3,5-diaminobenzoate (DBAE-9-branch-B) were introduced in these polyimides, and the homopolyimides based on BTDA/ DBAE-9-branch-A and BTDA/ DBAE-9-branch-B, and copolyimides containing more than $50 \%$ of DBAE-9-branch-A or DBAE-9-branch-B were soluble in NMP. Thus, it was found that the introduction of branched alkyl chains enhances solubility. 


\begin{tabular}{|c|c|c|c|c|c|c|c|c|c|c|}
\hline \multicolumn{2}{|c|}{ Diamine $^{a}$} & \multirow{4}{*}{$\begin{array}{c}\frac{\text { Poly(amic acid) }}{} \\
\frac{\eta_{\text {inh }}{ }^{\mathrm{b}}}{\mathrm{dLg}^{-1}}\end{array}$} & \multicolumn{8}{|c|}{ Polyimide } \\
\hline & & & \multirow{4}{*}{$\begin{array}{l}\text { Solubility } \\
\text { in NMP }\end{array}$} & \multirow{4}{*}{$\frac{\eta_{\text {inh }}{ }^{b}}{d L g^{-1}}$} & \multirow{4}{*}{$\frac{\mathrm{Tg}^{\mathrm{c}}}{{ }^{\circ} \mathrm{C}}$} & \multirow{2}{*}{\multicolumn{2}{|c|}{$\begin{array}{c}10 \% \text { Weight loss } \\
\text { temperature }^{\mathrm{d}}\end{array}$}} & & & \\
\hline Long-chain-DA & DDE & & & & & & & \multicolumn{3}{|c|}{ Molecular Weight $^{\mathrm{e}}$} \\
\hline \multicolumn{2}{|l|}{$\mathrm{mol} \%$} & & & & & in Air & in $\mathrm{N}_{2}$ & $M n$ & $M w$ & $M w / M n$ \\
\hline & & & & & & ${ }^{\circ} \mathrm{C}$ & ${ }^{\circ} \mathrm{C}$ & & & \\
\hline \multicolumn{11}{|l|}{ ADBP-12 } \\
\hline 0 & 100 & 1.15 & insoluble & & & & & & & \\
\hline 25 & 75 & 0.44 & insoluble & & & & & & & \\
\hline 50 & 50 & 0.49 & soluble & 0.37 & 264 & 467 & 500 & & & \\
\hline 75 & 25 & 0.49 & soluble & 0.46 & 261 & 469 & 481 & & & \\
\hline 100 & 0 & 0.34 & soluble & 0.37 & 254 & 468 & 464 & & & \\
\hline \multicolumn{11}{|l|}{ AODB-12 } \\
\hline 0 & 100 & 1.15 & insoluble & & & & & & & \\
\hline 25 & 75 & 0.39 & soluble & 0.29 & 262 & 460 & 456 & & & \\
\hline 50 & 50 & 0.21 & soluble & 0.23 & 264 & 456 & 457 & & & \\
\hline 75 & 25 & 0.14 & soluble & 0.19 & 284 & 447 & 452 & & & \\
\hline 100 & 0 & 0.14 & soluble & 0.16 & 277 & 436 & 441 & & & \\
\hline \multicolumn{11}{|l|}{ DBAE-12 } \\
\hline 0 & 100 & 1.15 & insoluble & & & & & & & \\
\hline 25 & 75 & 0.48 & insoluble & & & & & & & \\
\hline 50 & 50 & 0.45 & insoluble & & & & & & & \\
\hline 75 & 25 & 0.40 & insoluble & & & & & & & \\
\hline 100 & 0 & 0.31 & insoluble & & & & & & & \\
\hline \multicolumn{11}{|l|}{ ADBA-12 } \\
\hline 0 & 100 & 1.15 & insoluble & & & & & & & \\
\hline 25 & 75 & 0.95 & insoluble & & & & & & & \\
\hline 50 & 50 & 0.66 & soluble & 0.57 & $247^{\mathrm{f}}$ & 474 & 468 & 43700 & 97000 & 2.2 \\
\hline 75 & 25 & 0.59 & soluble & 0.36 & $260^{\mathrm{f}}$ & 452 & 435 & 27900 & 54200 & 1.9 \\
\hline 100 & 0 & 0.45 & insoluble & & & & & & & \\
\hline \multicolumn{11}{|l|}{ DPABA-12 } \\
\hline 0 & 100 & 1.15 & insoluble & & & & & & & \\
\hline 25 & 75 & 0.96 & insoluble & & & & & & & \\
\hline 50 & 50 & 0.83 & soluble & 0.65 & $253,241^{\mathrm{f}}$ & 453 & 446 & 45300 & 119100 & 2.6 \\
\hline 75 & 25 & 0.60 & soluble & 0.39 & $325^{\mathrm{f}}$ & 400 & 441 & 31500 & 77200 & 2.5 \\
\hline 100 & 0 & 0.53 & soluble & 0.37 & $247^{\mathrm{f}}$ & 352 & 429 & 25600 & 55300 & 2.2 \\
\hline
\end{tabular}

aEquimolar amount of BTDA (3.3',4,4'-Benzophenonetetracarboxylic dianhydride) was used to the total molar amount of diamine. Reaction condition; r.t., $12 \mathrm{~h}$ poly (amic acid), Pyridine (5 molar) / $\mathrm{Ac}_{2} \mathrm{O}$ (4 molar), $120^{\circ} \mathrm{C}$. bMeasured at $0.5 \mathrm{~g} \mathrm{dL}^{-1}$ in NMP at $30^{\circ} \mathrm{C}$. ${ }^{\mathrm{c}}$ Measured by DSC at a heating rate of 20 ${ }^{\circ} \mathrm{C} / \mathrm{min}$ in $\mathrm{N}_{2}$ on second heating. ${ }^{\mathrm{d}}$ Measured by TGA at a heating rate of $10^{\circ} \mathrm{C} / \mathrm{min}$. ${ }^{e}$ Determined by SEC in NMP containning $10 \mathrm{mM} \mathrm{LiBr}$ using a series of polystyrenes standards having narrow polydispersities. fSoftening temperature, measured by TMA at a heating rate of $10^{\circ} \mathrm{C} / \mathrm{min}$

Table 1. Polyimides and copolyimides bearing long-chain alkyl groups

\subsubsection{Molecular weight}

As an index of molecular weight, the measurement of inherent viscosities $\left(\eta_{\text {inh }}\right)$ and SEC measurement have been carried out in our laboratory. The inherent viscosities of all polymers were measured using Cannon Fenske viscometers at a concentration of $0.5 \mathrm{~g} / \mathrm{dL}$ in NMP at $30{ }^{\circ} \mathrm{C}$. Size exclusion chromatography (SEC) measurements were performed in NMP containing $10 \mathrm{mM} \mathrm{LiBr}$ at $40^{\circ} \mathrm{C}$ with a TOSOH HLC-8020 equipped with a TSK-GEL ALPHA-M. Number average molecular weight $(M n)$, weight average molecular weight $(M w)$ and polydispersity $(\mathrm{Mw} / \mathrm{Mn})$ were determined by TOSOH Multi Station GPC-8020 calibrated with a series of polystyrenes as a standard. For examples, $\eta_{\text {inh }}$ values for the 


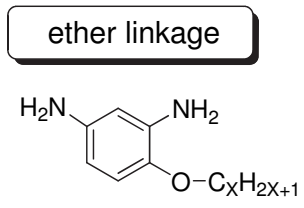

AODB-X

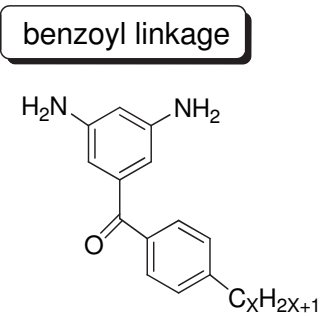

ADBP-X

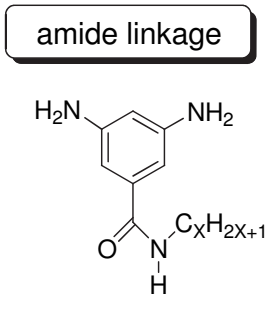

ADBA-X ester linkage<smiles>CCCCCCOC(=O)c1cc(N)cc(N)c1</smiles>

DBAE-X

\section{High}

\section{Low}

Fig. 6. Effect of aromatic diamines bearing long-chain alkyl groups on polyimide solubility

soluble polyimides in Table 1 are in the range of $0.16 \sim 0.65 \mathrm{dLg}^{-1}$. The weight average molecular weights of the polyimides based on ADBA-12 and DPABA-12 determined by SEC measurements are in the range of 54200 to 119100 . These values indicated that the molecular weights of these polyimides were considered to be medium or rather lower values for polyimides, however, all polyimides show good film formation ability. In almost all cases, the molecular weights increased with the percentage of DDE, i. e. highly reactive diamine. The representative SEC traces are shown in Fig. 7, indicating that copolyimides based on BTDA/ADBA-11/DDE have typical monomodal molecular weight distribution, and their polydispersity is in the range of 2.2-2.4, which are typical values for polycondensation polymers.

\subsubsection{Spectral analysis}

${ }^{1} \mathrm{H}$ NMR spectra were measured on a JEOL JNM-AL400 FT NMR instrument in $\mathrm{CDCl}_{3}$ or dimethylsulfoxide- $\mathrm{d}_{6}$ with tetramethylsilane (TMS) as an internal standard. IR spectra were recorded on a JASCO FT/IR-470 plus spectrophotometer. ATR Pro 450-S attaching Ge prism was used for the ATR measurements of polyimide films.

The polyimide film samples for the measurement of ATR and thermomechanical analysis (TMA) mentioned in the next section were prepared by the following casting method. About five wt \% polyimide solution in appropriate solvents such as NMP, chloroform, $m$-cresol on aluminum cup or glass substrate and the solution were slowly evaporated by heating on a hotplate at appropriate temperature $\left(\mathrm{ca} .50^{\circ} \mathrm{C}\right.$ for chloroform, $\mathrm{ca} .150{ }^{\circ} \mathrm{C}$ for NMP and $\mathrm{m}$ cresol) until the films were dried, then the films were dried in a vacuum oven at $100{ }^{\circ} \mathrm{C}$ for $12 \mathrm{~h}$. In case the molecular weights of polyimides were lower, the polyimide films tended to be brittle.

In the case of soluble polyimides, NMR measurements are convenient because solution samples can be prepared, and provide more quantitative data. For example, Fig. 8 shows the ${ }^{1} \mathrm{H}$ NMR spectrum of the copolyimide based on ADBA-12/DDE (50/50) that is soluble in DMSO- $\mathrm{d}_{6}$ and the peaks support this polymer structure. The intensity ratio of $\mathrm{CH}_{3}$ protons 


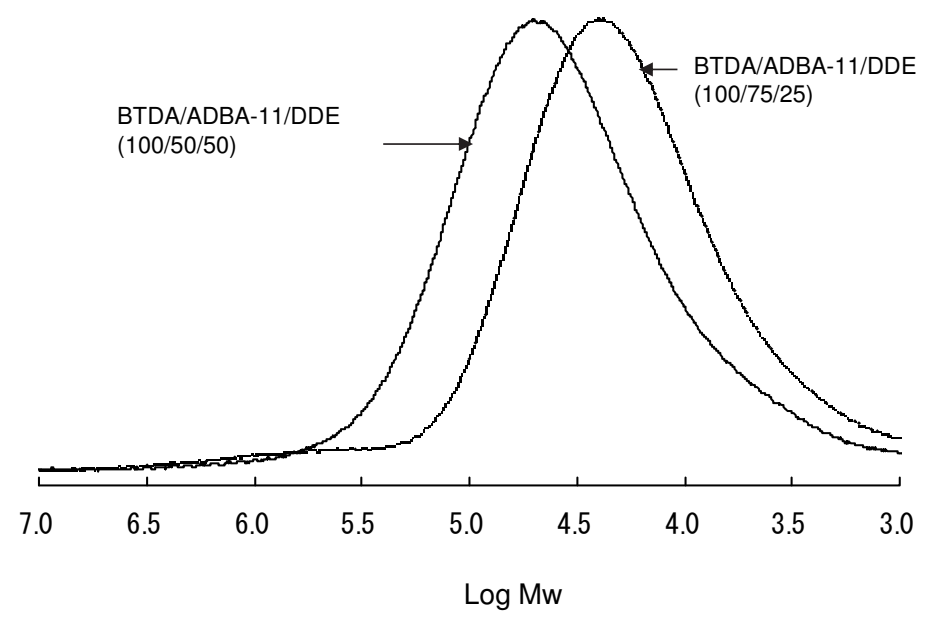

Fig. 7. Representative SEC traces of soluble polyimides based on aromatic diamines bearing long-chain alkyl groups. BTDA/ADBA-11/DDE (100/50/50): $M n, 49500 ; M w, 118800$; $M w / M n$, 2.4. BTDA/ADBA-11/DDE (100/75/25): $M n, 30700 ; M w, 67900 ; M w / M n, 2.2$

of long-chain alkyl groups and the aromatic proton $\mathrm{H}_{\mathrm{A}}$ or $\mathrm{H}_{\mathrm{B}}$ is approximately $3 / 4$, meaning that copolymer composition corresponds to the monomers initial ratio. Imidization ratios of polyimides are generally determined by FT-IR measurements, comparing absorption intensities of amic acid carbonyl groups with those of imide carbonyl groups. However, FTIR measurements give relatively less quantitative data in comparison with NMR measurements. In the case of these soluble polyimides, generally, a broad signal due to the $\mathrm{NH}$ protons of poly(amic acid) appears around $12 \mathrm{ppm}$ in DMSO- $\mathrm{d}_{6}$, while this signal disappears in the corresponding polyimide. The imidization ratios of these polyimides can be calculated from the reduction in intensity ratio of the $\mathrm{NH}$ proton signals in poly(amic acid)s and these values for the polyimides prepared in our laboratory are sufficiently high, near to $100 \%$.

ATR measurement is the useful method to measure IR spectrum of polymer films. Representative ATR spectrum of dendronized polyimides based on 12G1-AGTerphenyldiamine and 12G2-AG-Terphenyldiamine were shown in Fig. 9 and these spectrum show the strong absorptions based on $\mathrm{C}-\mathrm{H}$ bonds of long-chain alky groups and the strong absorptions of $\mathrm{C}-\mathrm{O}$ bonds of alkyloxy groups, and these absorption intensities become stronger with the increase of long-chain alkyl ether segments in the polyimides.

\subsubsection{Thermal properties}

Differential scanning calorimetery (DSC) traces were obtained on a Shimadzu DSC-60 under nitrogen (flow rate $30 \mathrm{~mL} / \mathrm{min}$ ) at a heating rate of $20^{\circ} \mathrm{C} / \mathrm{min}$ and the glass transition temperatures $(\mathrm{Tg})$ were read at the midpoint of the heat capacity jump from the second heating scan after cooling from $250 \circ$. Thermomechanical analysis (TMA) was performed on a Shimadzu TMA-50 under nitrogen $(30 \mathrm{~mL} / \mathrm{min})$ at a heating rate of $10{ }^{\circ} \mathrm{C} / \mathrm{min}$ with a 
(n)
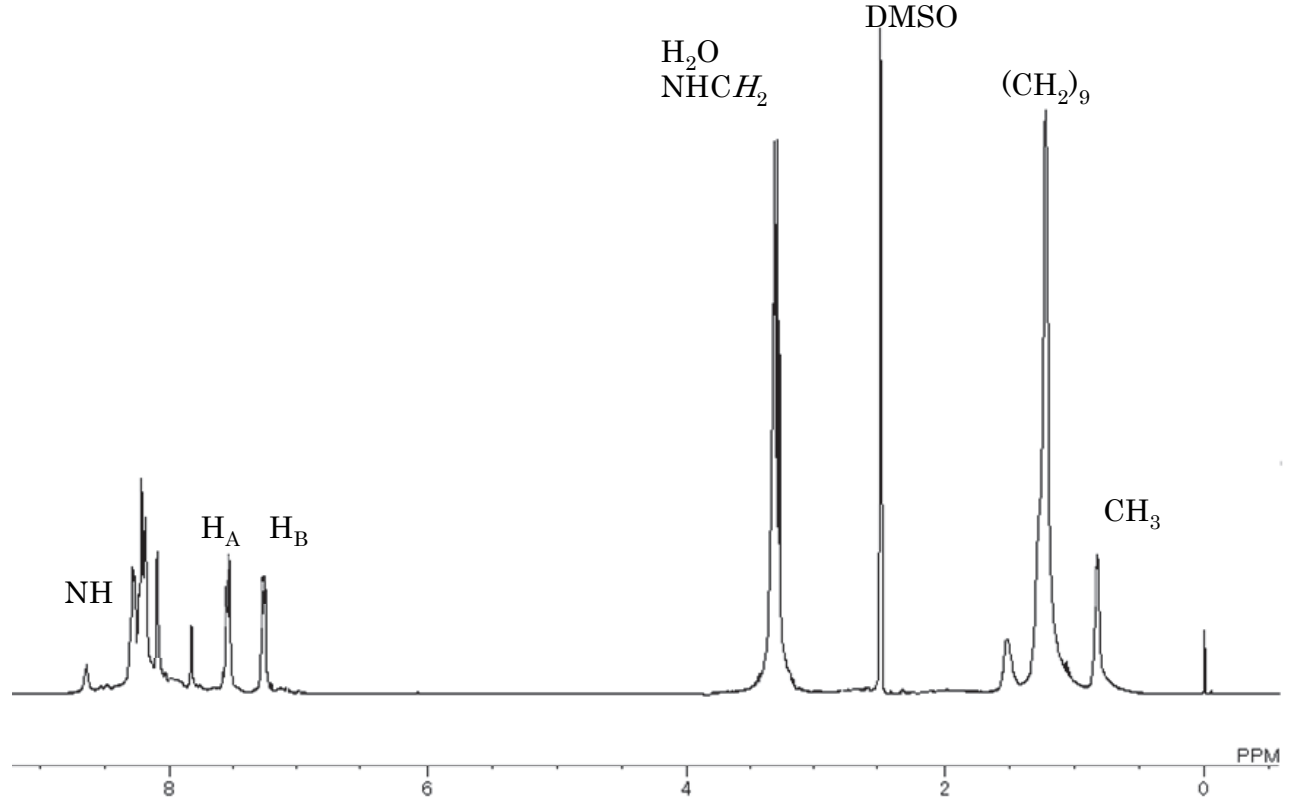

Fig. 8. ${ }^{1} \mathrm{H}$ NMR spectrum of a copolyimide based on BTDA/ADBA-12/DDE (100/50/50)

$10 \mathrm{~g}$ load in the penetration mode using the film samples approximately $300 \mu \mathrm{m}$ in thickness. Softening temperatures (Ts) were taken as the onset temperature of the probe displacement on the second TMA scan after cooling from $220{ }^{\circ} \mathrm{C}$. Thermogravimetric analysis (TGA) was performed on a Shimadzu TGA-50 in air or under nitrogen $(50 \mathrm{~mL} / \mathrm{min})$ at a heating rate of $10{ }^{\circ} \mathrm{C} / \mathrm{min}$ using $5 \mathrm{mg}$ of a dry powder sample, and 0 (onset), $5,10 \%$ weight loss temperatures $\left(\mathrm{Td}_{0}, \mathrm{Td}_{5}, \mathrm{Td}_{10}\right)$ were calculated from the second heating scan after cooling from $250 \circ \mathrm{C}$.

The Tg's of these polyimides sometimes were not recognized by DSC measurements, probably due to the rigid imide linkages. In these cases, TMA measurements were performed to determine the Tg. Many publications have described that the softening temperature (Ts) obtained from TMA measurements corresponds to the apparent $\mathrm{Tg}$ of polymers. As can be seen from Tables 1 , the Tg values of these polyimides are in the range from $241-325{ }^{\circ} \mathrm{C}$, showing similar values observed in soluble polyimides obtained from our laboratory ( $\mathrm{ca}$. around $250{ }^{\circ} \mathrm{C}$ ) and are 100-150 ${ }^{\circ} \mathrm{C}$ lower than those of the conventional fully aromatic polyimides, however, are $100-150{ }^{\circ} \mathrm{C}$ higher than the commodity thermoplastics. 


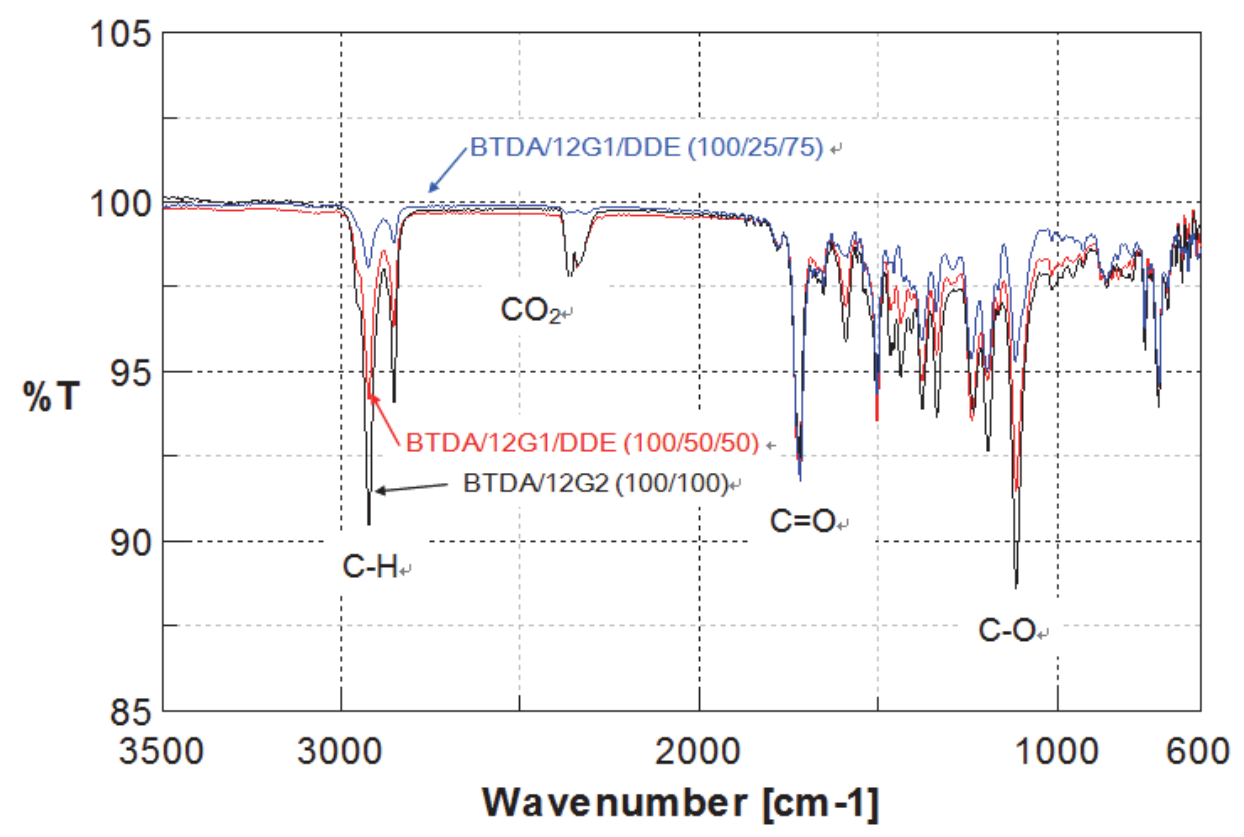

Fig. 9. Representative ATR spectrum of dendronized polyimides

Consequently, the physical heat resistance of these soluble polyimides bearing long-chain alkyl groups can be ranked as heat resistant polymers.

The $\mathrm{Td}_{10}$ values of these polyimides bearing long-chain alkyl groups in Table 1 are in the range $352 \sim 474{ }^{\circ} \mathrm{C}$ in air and $429 \sim 500{ }^{\circ} \mathrm{C}$ under nitrogen, showing similar values observed in soluble polyimides obtained from our laboratory ( $c a .400 \sim 500 \circ \mathrm{C})$. In most cases, $\mathrm{Td}$ values in air were lower than $\mathrm{Td}$ values under nitrogen following the general fact that oxidative degradation proceed rapidly in air. As the incorporation of DDE resulted in a reduction of aliphatic components of the polyimides, the $\mathrm{Td}_{10}$ of these polyimides tends to increase with the increment of the DDE component (Table 1 ). These $\mathrm{Td}_{10}$ values of soluble polyimides obtained in our laboratory are 100 200 ${ }^{\circ} \mathrm{C}$ lower than those of wholly aromatic polyimides; however, the chemical heat resistance of these polyimides still can be ranked as heat resistant polymers. Fig. 10 shows the TGA traces of dendronized polyimides based on BTDA/12G1-AG-Terphenyldiamine (100/50/50). These TGA traces showed steep weight loss at the intial stage of degradation, and these weight loss percent almost correspond the calculated value of the weight percent of alkyl groups in polymer segments. Therefore, it is considered that the degradation of long-chain alkyl groups occurred at the initial stage of thermal degradation. Furthermore, these TGA traces also show the evidence that the longchain alkyl groups exist in the polyimides and the cleavage of alkyl groups did not occurred during the polymerization.

\subsection{Application for VAN-LCDs}

The alignment layer application for VAN-LCDs using polyimides having dendritic side chains was performed at Cheil Ind. Inc., Korea. LCDs test cell properties were measured as 


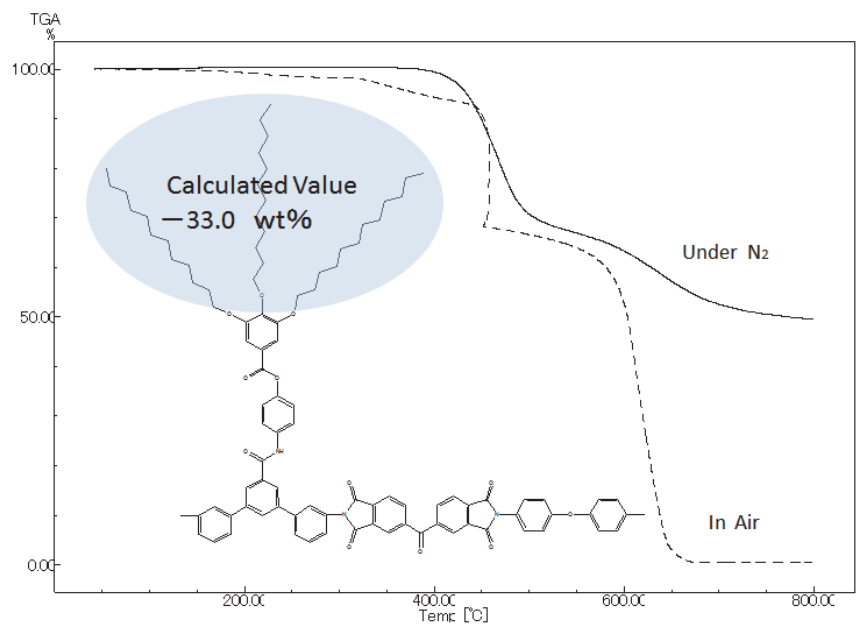

Fig. 10. Representative TGA traces of dendronized polyimides based on 12G1-AGTerphenyldiamine \{(BTDA/12G1-AG-Terphenyldiamine/DDE (100/50/50)\}

follows: the polyimide solutions were spin-coated onto ITO glass substrates to a thickness of $0.1 \mu \mathrm{m}$, and cured at $210{ }^{\circ} \mathrm{C}$ for 10 minutes to produce liquid crystal alignment films. After the liquid crystal alignment films were subjected to a rubbing process, the alignment properties and the pretilt angles of the liquid crystal were measured. The surface of the alignment films were rubbed by means of a rubbing machine, two substrates were arranged anti-parallel to each other in such a manner that the rubbing direction of the each substrates were reverse, and the two substrates were sealed while maintaining cell gaps of $50 \mu \mathrm{m}$ to fabricate liquid crystal cells. The liquid crystal cells were filled with the liquid crystalline compounds (Merk licristal). The alignment properties of the liquid crystal were observed under an orthogonally polarlized optical microscope. The pretilt angles of the liquid crystal were measured by a crystal rotation method. In order to examine the electrical properties, the test cells were prepared by the same manner as above except the cell gap, $5 \mu \mathrm{m}$. The voltage holding ratios were measured with VHRM 105 (Autronic Melchers). To evaluate the VHR, the applied frequency and voltage was $60 \mathrm{~Hz}, 1 \mathrm{~V}$ with pulse of $64 \mu \mathrm{sec}$. The voltage versus transmittance and optical response properties, such like contrast ratio, response time, image sticking, etc., were measured using computer-controlled system in conjunction with an tungsten-halogen lamp, a function/arbitrary waveform generator, photomultiplier. The residual DCs were measured by $\mathrm{C}-\mathrm{V}$ method using impedance analyzer.

The polyimide alignment layers containing $8 \mathrm{~mol} \%$ of 12G1-AG-Terphenyldiamine were utilized for the vertical alignment mode (VA-mode). The synthesis of polyimide alignment layers containing $8 \mathrm{~mol} \%$ of 12G1-AG-Terphenyldiamine was carried out in NMP as a solvent by conventional two step polymerization method regularly used for the synthesis of polyimide alignment layers for TN-LCDs, and 12G1-AG-Terphenyldiamine monomer was used as one of the diamine components. LCDs test cell properties are summarized in Table 2 . PIA-DEN represents the test cell using the polyimide alighnment layers containing $8 \mathrm{~mol} \%$ of 12G1-AG-Terphenyldiamine, and TN represents the test cell using the regular polyimide alignment layers. The pretilt angles of LC molecules were over $89^{\circ}$ in PIA-DEN test cells, which are the suitable values for VAN-LCDs. It is speculated that an extremely 


\begin{tabular}{|c|c|c|}
\hline ITEM & PIA-DEN & TN mode \\
\hline Pretilt angle $\left(^{\circ}\right)$ & $>89$ & $4 \sim 6$ \\
\hline Surface energy $\left(\mathrm{dyn} / \mathrm{cm}^{2}\right)^{\mathrm{a}}$ & 39 & 48 \\
\hline $\operatorname{VHR}(\%) \quad 25^{\circ} \mathrm{C}$ & $>99$ & $>99$ \\
\hline $60^{\circ} \mathrm{C}$ & $>98$ & $>95$ \\
\hline Response time (ms) & $<25$ & $<30$ \\
\hline Contrast ratio & 580 & 250 \\
\hline Residual DC (mv) & $<200$ & $<200$ \\
\hline Image sticking & $<1$ & $<1$ \\
\hline
\end{tabular}

${ }^{\text {a }}$ Surface energy of polyimide alignment films measured by a contact angle metod

Table 2. LCDs test cell properties using the alignment films containing dendronized polyimides

bulky and hydrophobic dendritic moieties affects the generation of pretilt angles between the surface of polyimide and liquid crystalline molecules as illustrated in Fig. 11. The considerably lower surface energy value of the PIA-DEN alignment film in comparison with the one of $\mathrm{TN}$ mode also indicate that the surface of polyimides containing dendritic moieties is more hydrophobic.

The various important properties of PIA-DEN test cells such as voltage holding ratio (VHR), response time, contrast ratio, residual DC, and image sticking are equivalent or advantageous in comparison with those of regular TN test cell. Fig. 12 shows a V-T (voltagetransmittance) curve of these test cells, and shows a dramatic change of T. Consequently, it is convinced that the dendritic monomers, and dendritic polyimides developed by our research can be applied for the alignment films for VAN-LCDs.

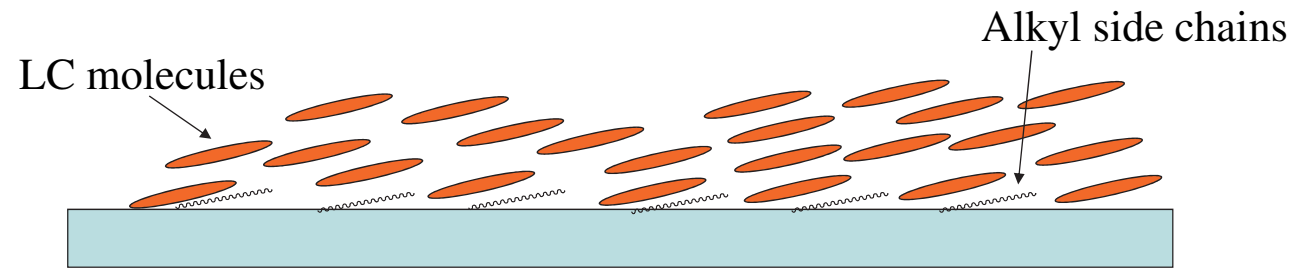

PI alignment films having alkyl side chains for TN-LCDs

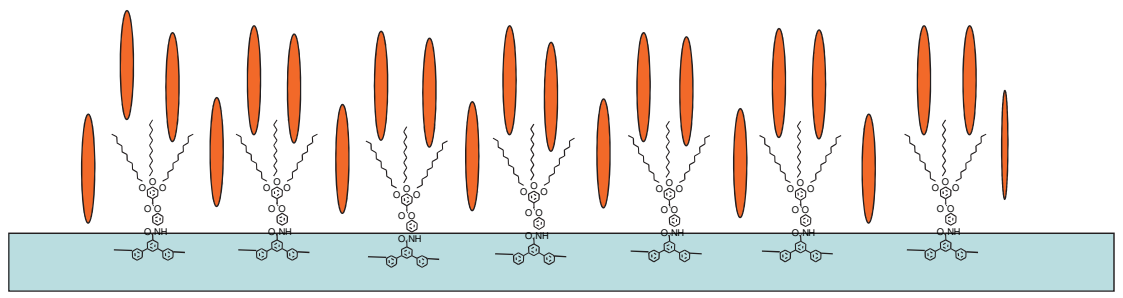

Dendronized PI alignment films for VAN-LCDs

Fig. 11. Vertical alignment of LC molecules using dendronized polyimides as alignment layers 


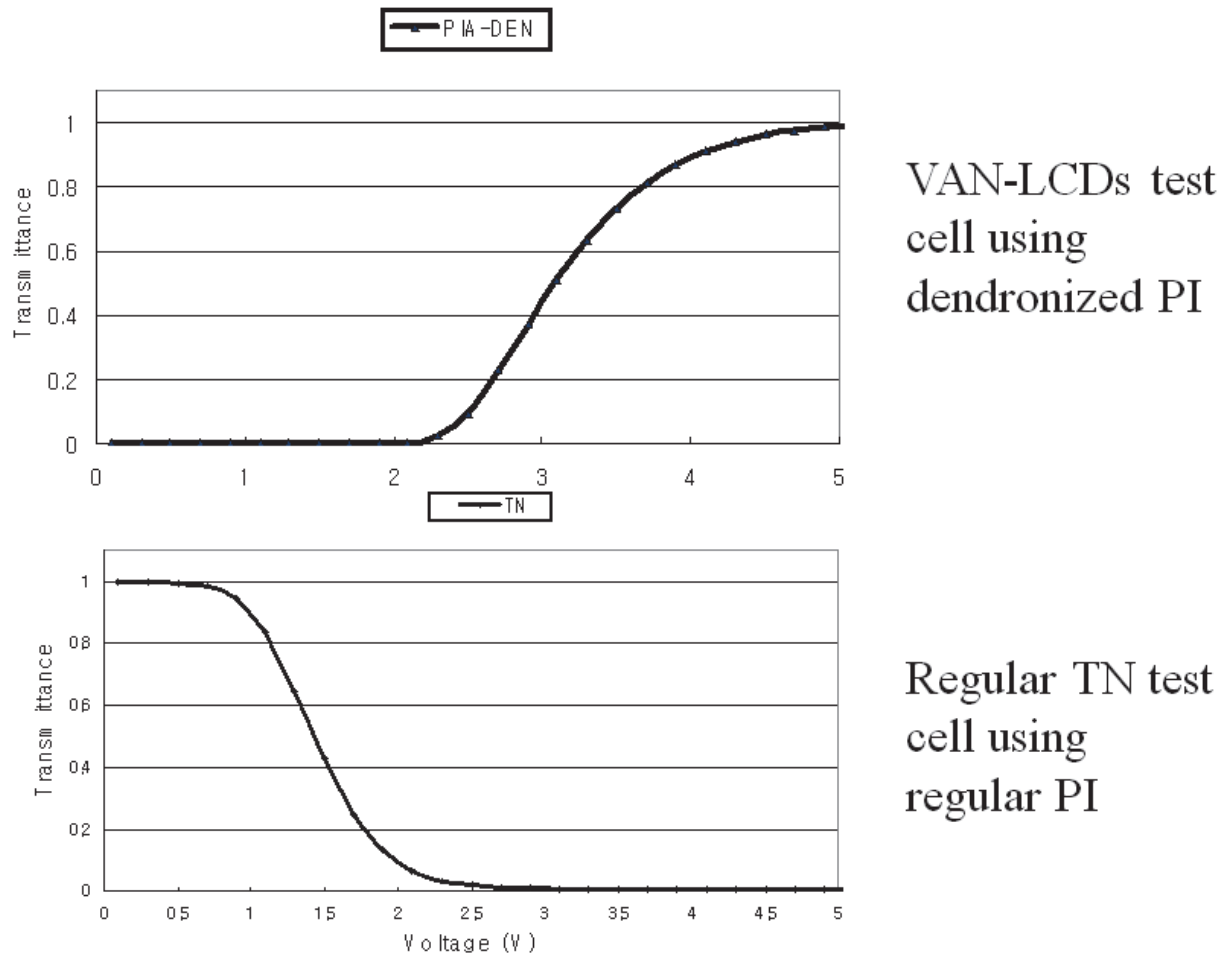

Fig. 12. Voltage-transmittance curves of LCD test cells using dendronized and conventional polyimides

\subsection{Application for printed electronics}

Recently, various printing methods such as an ink-jet print method have been investigated for manufacturing polymeric thin-films, and the surface wettability and their control methods have become important. Thus, the author has investigated the surface wettability control of these polyimides by UV light irradiation that is a conventional method for microlithography (Fig. 13). The soluble polyimides bearing long-chain alkyl groups used for this study were synthesized from 12G1-AG-Terphenyldiamine, $3 \mathrm{C}_{10}$-PEPEDA, $3 \mathrm{C}_{10}$ PEPADA or $3 \mathrm{C}_{10}$-PAPADA that have three long-chain alkyl groups, aliphatic tetracarboxylic dianhydride; Cyclohexene-DA or aromatic tetracarboxylic dianhydride; DSDA or 3,4'ODPA, and DDE as a diamine co-monomer. Polyimide thin-films were obtained as follows: 0.5-2.0 wt \% polyimide solution in NMP were cast on glass substrates and the solution were slowly evaporated by heating at approximately 100-120 $\mathrm{\circ}$ until the films were dried, then the films were dried in a vacuum oven at $100{ }^{\circ} \mathrm{C}$ for $12 \mathrm{~h}$. Water contact angles were measured by SImage mini (Excimer. Inc., Japan) and UV light irradiation were performed using UV lamp unit E50-254-270U-1 (254 nm, $6.0 \mathrm{~mW} / \mathrm{cm}^{2}$, Excimer. Inc., Japan) and a cool plate NCP-2215 (NISSIN Laboratory equipment, Japan) adjusted at $20^{\circ} \mathrm{C}$ that was used to neglect the effect of thermal degradation of polyimide films during UV irradiation process. 

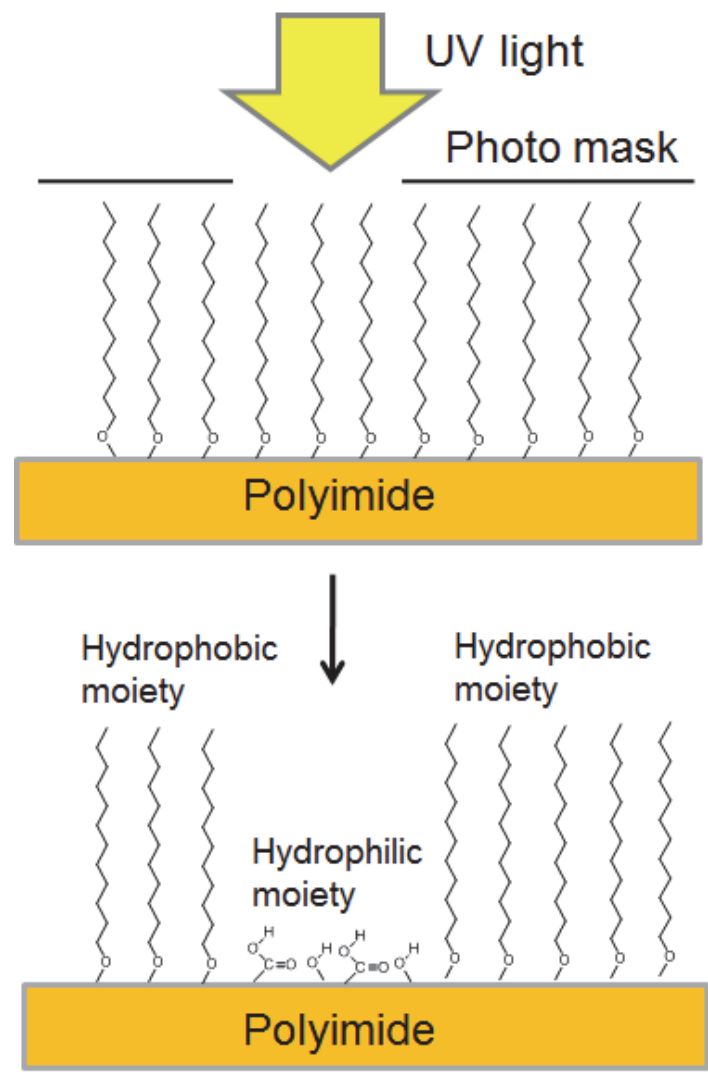

Fig. 13. Conceptual scheme of wettability control of the polyimide surface by UV irradiation

Thus, the polyimide thin films were irradiated by UV light, and the contact angles for the water decreased from near $100^{\circ}$ (hydrophobicity) to the minimum value, $20^{\circ}$ (hydrophilicity) in proportion to irradiated UV light energy. The thin film specimens after UV light irradiation were rinsed by isopropyl alcohol. The representative results using the polyimides based on $3 C_{10}$-PEPADA are summarized in Table 3 and Fig. 14.

Although the water contact angles decreased after UV light irradiation, the degrees of changes depended on the polyimide structures. For examples, the contact angles of the polymides based on 3,4'-ODPA or DSDA/ $3 \mathrm{C}_{10}$-PEPADA /DDE remarkably decreased from around $100^{\circ}$ to around $20-30^{\circ}$ after UV light irradiation $(254 \mathrm{~nm}, 2-8 \mathrm{~J})$. These changes were less in the case of the polyimides based on Cyclohexene-DA/3 $\mathrm{C}_{10}$-PEPADA /DDE, and the changes were much less in the case of the polyimides based on Cyclohexene-DA/ DDE without long-chain alkyl groups.

It is considered that these changes of wettability of polyimides are mainly based on the photo-degradation or scission of long-chain alkyl groups, and that the generation of the hydrophilic functional groups such as $\mathrm{COOH}$ and $\mathrm{OH}$ groups occurred. ATR measurements 


\begin{tabular}{|c|c|c|c|c|c|c|c|}
\hline \multicolumn{3}{|c|}{ Monomer } & \multicolumn{5}{|c|}{ Polyimide } \\
\hline \multirow[t]{2}{*}{ Tetracarboxylic dianhydride $^{\mathrm{a}}$} & \multicolumn{2}{|l|}{ Diamine } & \multicolumn{5}{|c|}{ Water contact angle after UV irradiation $^{\mathrm{b}},()^{\mathrm{c}}$} \\
\hline & \multicolumn{2}{|l|}{$\mathrm{mol} \%$} & $0 \mathrm{~J}$ & $2 \mathrm{~J}$ & $4 \mathrm{~J}$ & $6 \mathrm{~J}$ & $8 \mathrm{~J}$ \\
\hline \multirow[t]{4}{*}{ Cyclohexene-DA } & $3 \mathrm{C}_{10}$-PEPADA & $\overline{\mathrm{DDE}}$ & & & & & \\
\hline & 100 & 0 & $104(101)$ & $96(92)$ & $95(83)$ & $86(67)$ & $81(50)$ \\
\hline & 50 & 50 & $97(96)$ & $95(81)$ & $87(64)$ & $68(59)$ & $57(38)$ \\
\hline & 0 & 100 & $80(80)$ & $73(75)$ & $67(60)$ & $58(50)$ & $38(24)$ \\
\hline \multirow{4}{*}{$\overline{\text { DSDA }}$} & $3 \mathrm{C}_{10}$-PEPADA & DDE & & & & & \\
\hline & 100 & 0 & 104 (104) & $88(79)$ & $76(64)$ & $60(45)$ & $44(33)$ \\
\hline & 50 & 50 & $99(95)$ & $87(76)$ & $81(72)$ & $62(60)$ & $45(54)$ \\
\hline & 0 & 100 & & & & & \\
\hline \multirow[t]{4}{*}{$3,4^{\prime}$-ODPA } & $3 \mathrm{C}_{10}$-PEPADA & DDE & & & & & \\
\hline & 100 & 0 & $100(99)$ & $80(75)$ & $57(57)$ & $36(30)$ & $24(23)$ \\
\hline & 50 & 50 & $96(94)$ & $80(73)$ & $52(57)$ & $31(32)$ & $31(30)$ \\
\hline & 0 & 100 & $78(78)$ & $77(75)$ & $44(70)$ & $42(63)$ & $36(52)$ \\
\hline
\end{tabular}

a Equimolar amount of tetracarboxylic dianhydride was used to the total amount of diamines. ${ }^{\mathrm{b}}$ Water contact angles (deg) using contact angle meter (Excimer inc.,SImage mini)at $25^{\circ} \mathrm{C}$. ${ }^{c}$ Water contact angles (deg) after rinsing by isopropyl alcohol.

Table 3. Water contact angles of the polyimide surface after irradiation of UV light

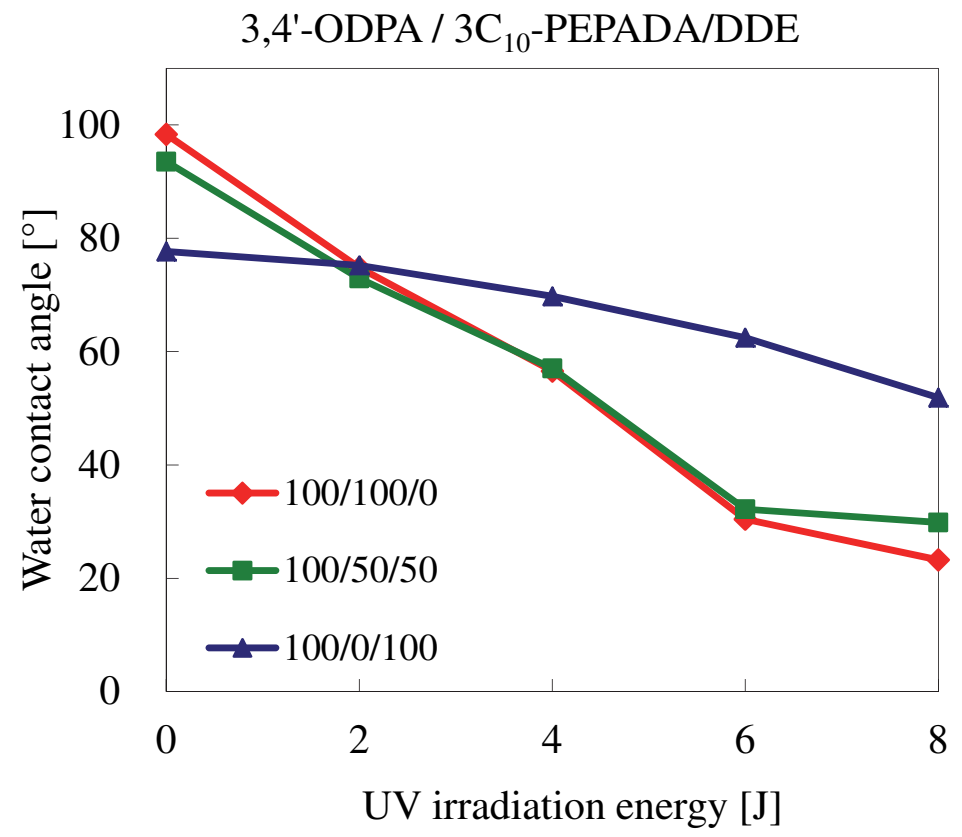

Fig. 14. UV irradiation energy dependence of water contact angles of polyimide films 
of the polyimide surfaces after UV light irradiation support this assumption, and the absorption of $\mathrm{OH}$ groups around $3300 \mathrm{~cm}^{-1}$ increase, the absorption of alkyl groups around $2900 \mathrm{~cm}^{-1}$ decrease, and the absorption of ether groups around $1200 \mathrm{~cm}^{-1}$ decrease with the increase in the photo-irradiation energy (Fig. 15). The intensive surface analysys was examined using XPS and SFM. XPS measurements were carried out on an XPS -APEX (Physical Electronics Co. Ltd.) with an Al Ka X-ray source (150 W). Chamber pressure; 10-9 10-10 Pa; take off angles; 45 and SFM (SII Nanotechnology Inc., SPA 400) was operated in a dynamic force microscopic (DFM) mode. The generation of hydrophilic moieties was analyzed in detail by XPS narrow scan, and chemical shifts due to $\mathrm{C}-\mathrm{O}$ and $\mathrm{C}=\mathrm{O}$ bonds clearly increase after UV light irradiation (Fig. 16). The surface nm size roughness probably based on long-chain alky groups was observed by SFM analysis (Fig. 17), however, these micro roughness seemed not to change after UV light irradiation. Thus, the change of surface wettability of polyimides is occurred mainly by the changes of chemical structures of polyimide surface. It is speculated that the complicated photo-induced reactions such as auto-oxidation, cleavage of ester groups, Fries rearrangement, etc. occur on the surface of polyimides on the course of UV light irradiation (Fig. 18).

In conclusion, the surface wettability of polyimides bearing long-chain alkyl groups can be controlled by UV light irradiation, and these methods are expected to be applied in the field of printed electronics.

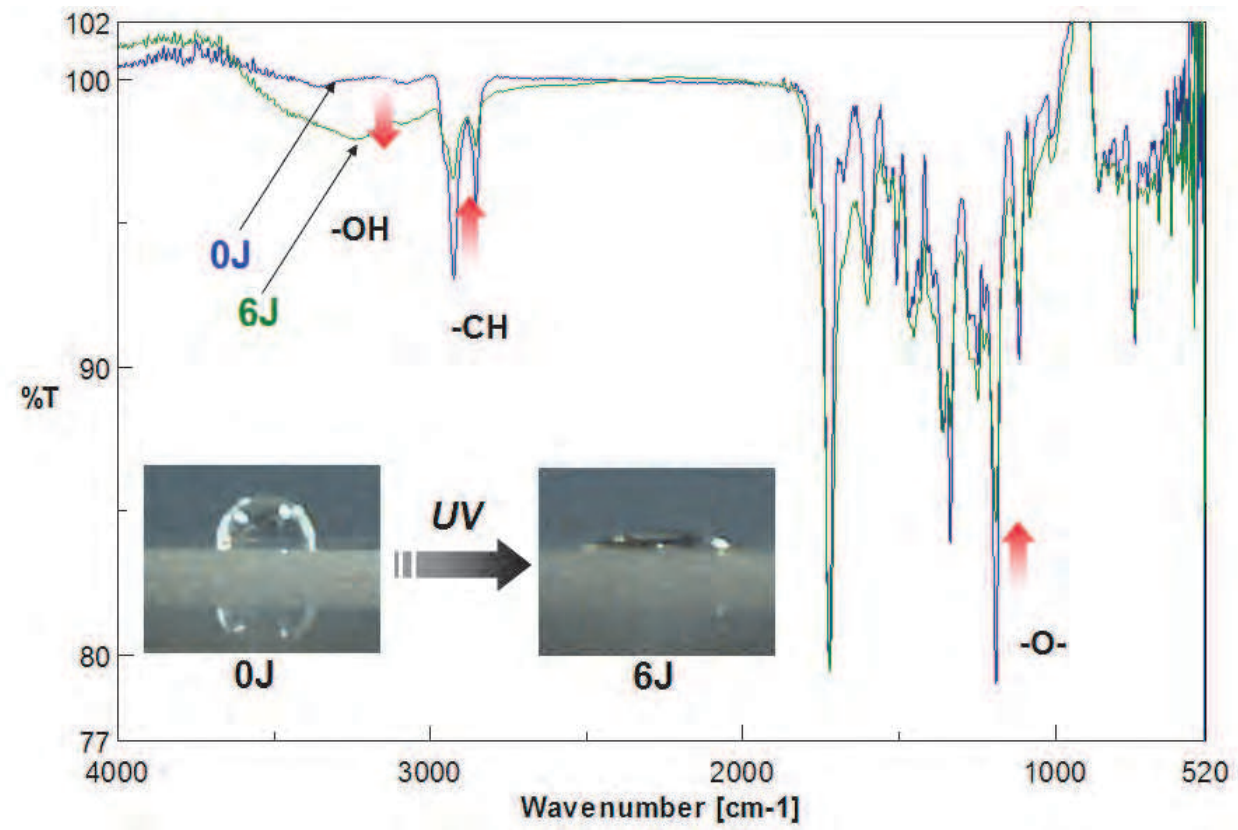

Fig. 15. Representative ATR spectrum of polyimides bearing long-chain alkyl groups before and after UV irradiation 
Polyimides Bearing Long-Chain Alkyl Groups and

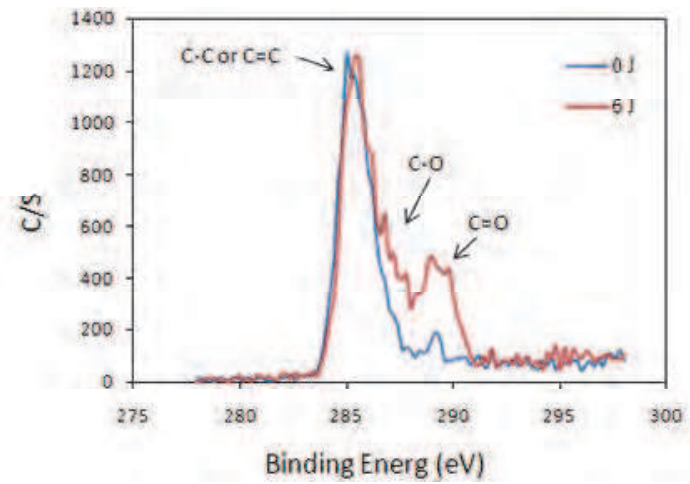

Fig. 16. XPS narrow scan of 3,4'-ODPA / $3 C_{10}$-PEPADA

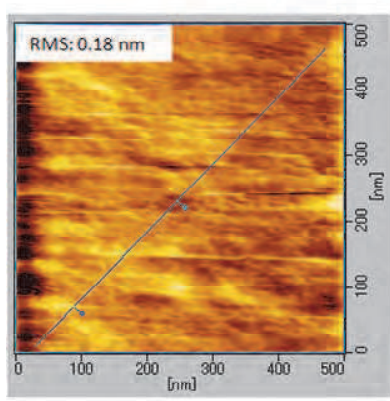

$3,4^{\prime}-O D P A / D D E(0 J)$

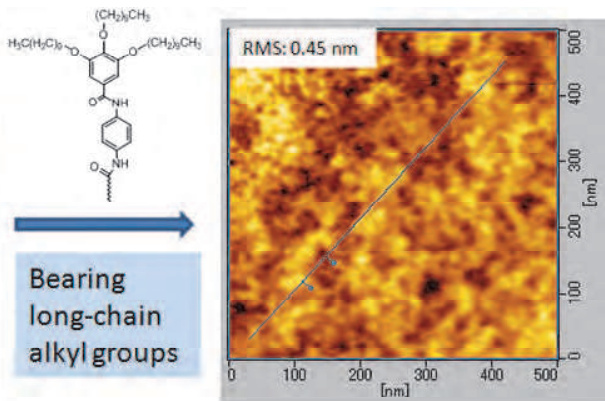

3,4'-ODPA / $3 C_{10}$-PAPADA (0 J)
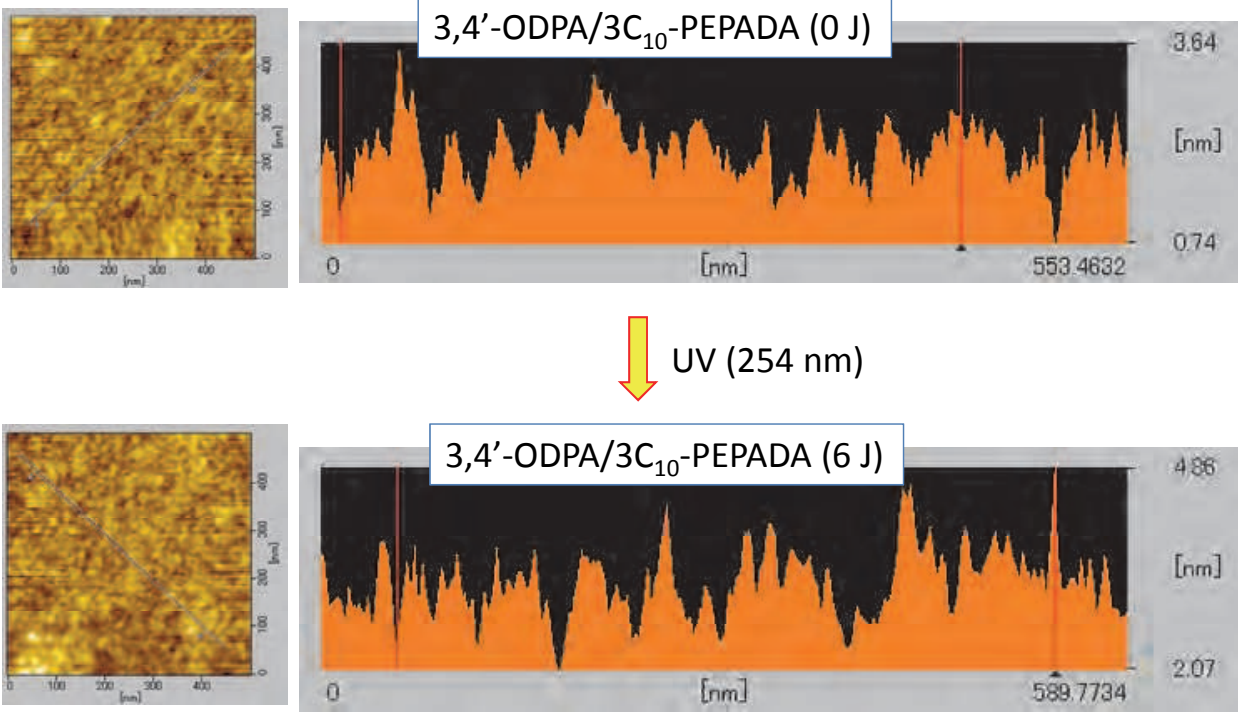

Fig. 17. SFM images of 3,4'-ODPA /DDE and 3,4'-ODPA / $3 C_{10}-$ PAPADA 


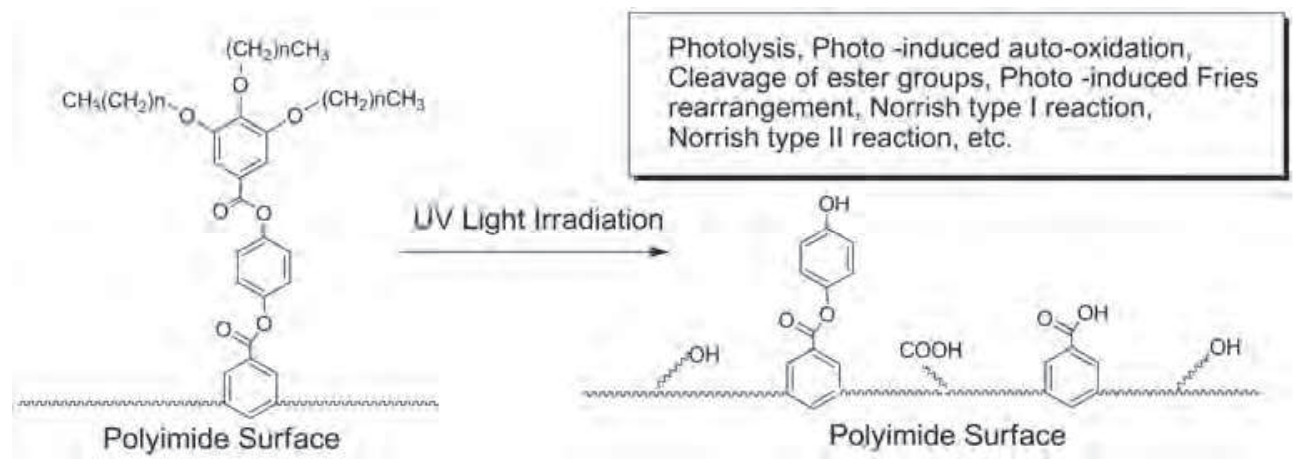

Fig. 18. Anticipated photochemical reactions on the surface of polyimides

\section{Conclusion}

The synthesis, characterizations, basic properties and applications of soluble polyimide bearing long-chain alkyl groups are reviewed in this chapter. These polyimides are successfully obtained based on the novel aromatic diamine monomers having long-chain alkyl groups. As these polyimides are soluble in various organic solvents, the spectral analyses such as NMR are possible, and the polymer structures are well characterized. The basic properties of these polyimides such as the solubility and the thermal stability are investigated in detail and the structure-properties relationships are well considered. Thus, it is concluded that these polyimides bearing long-chain alkyl groups are suitable polymeric materials for microelectronics applications.

The application as alignment layers for LCDs was investigated, and it was found that these polyimides having dendritic side chains were applicable for the vertically aligned nematic liquid crystal displays (VAN-LCDs). It is speculated that an extremely bulky and hydrophobic dendron moiety affects the generation of vertical alignment.

The thin films of polyimides bearing three long-chain alkyl groups were irradiated by UV light, and the contact angles for the water decreased from near $100^{\circ}$ (hydrophobicity) to 
near $20^{\circ}$ (hydrophilicity) in proportion to irradiated UV light energy. From the result of surface analyses, it is recognized that the hydrophobic long-chain alkyl groups on the polyimide surface decrease and the hydrophilic groups such as a hydroxyl group generate on their surface. Thus, the surface wettability of polyimides bearing long-chain alkyl groups can be controlled by UV light irradiation, and these methods are expected to be applied in the field of printed electronics.

\section{Acknowledgment}

The author thanks Dr. Atsushi Takahara of Kyushu University, Drs. Takaaki Matsuda and Tsutomu Ishi-I of Kurume National College of Technology for various advices. The author also thanks many students of Kurume National College of Technology for their help with the experiments. Financial supports from Cheil Industries Inc., Kyushu Industrial Technology Center, DYDEN Corporation, and Toyohashi University of Technology are gratefully acknowledged.

\section{References}

Tsuda, Y., Kawauchi, T., Hiyoshi, N. \& Mataka, S. (2000a). Soluble Polyimides Based on Alkyldiaminobenzophenone. Polymer Journal. Vol. 32, No. 7, (June 2000), pp. 594601, ISSN 0032-3896

Tsuda, Y., Kanegae, K. \& Yasukouchi, S. (2000b). Soluble Polyimides Based on Alkyloxydiaminobenzene. Polymer Journal. Vol. 32, No. 11, (November 2000), pp. 941-947, ISSN 0032-3896

Tsuda, Y., Kojima, M. \& $\mathrm{O}_{\mathrm{H}}$ J.-M. (2006). Soluble Polyimides Based on Diaminobenzoic Acid Alkylester. Polymer Journal. Vol. 38, No. 10, (October 2000), pp. 1043-1054, ISSN 0032-3896

Tsuda, Y., Kojima, M., Matsuda, T. \& OH, J.-M. (2008). Soluble Polyimides Based on Longchain Alkyl Groups via Amide Linkages. Polymer Journal. Vol. 40, No. 4 (April 2008), pp. 354-366, ISSN 0032-3896

Tsuda, Y. (2009). Soluble Polyimides Based on Aromatic Diamines Bearing Long-chain Alkyl Groups, In: Polyimides and Other High Temperature Polymers. Vol. 5, Mittal, K. L. (Ed.), pp. 17-42,VSP/Brill, ISBN 978-90-04-17080-3, Leiden

Tsuda, Y., $\mathrm{O}_{\mathrm{H}}$, J.-M. \& Kuwahara, R. (2009). Dendronized Polyimides Bearing Long-chain Alkyl Groups and Their Application for Vertically Aligned Nematic Liquid Crystal Displays. International Journal of Molecular Sciences. Vol. 10 (November 2009), pp. 5031-5053, ISSN 1422-0067

Tsuda, Y., Nakamura, R., Osajima, S. \& Matsuda, T. (2010). Surface Wettability Controllable Polyimides Bearing Long-chain Alkyl Groups by UV Light Irradiation. PMSE Preprints (ACS Division Proceeding Online), Vol. 239, ISSN 1550-6703, San Francisco, April 2010

Tsuda, Y., Hashimoto \& Matsuda, T. (2011a). Surface Wettability Controllable Polyimides Bearing Long-chain Alkyl Groups by UV Light Irradiation. Kobunshi Ronbunshu (Japanese), Vol. 68 (January 2011), pp. 24-32, ISSN 0386-2186 
Tsuda, Y. (2011b). Surface Wettability Controllable Polyimides Bearing Long-chain Alkyl Groups by UV Light Irradiation. Proceedings of International Conference on Materials for Advanced Technologies, ISBN 978-981-08-8878-7, SUNTEC Singapore, June 2011. 


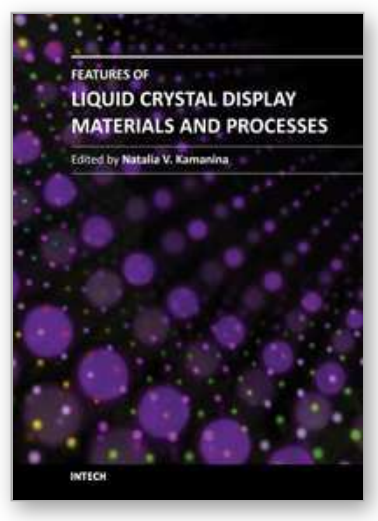

\section{Features of Liquid Crystal Display Materials and Processes}

Edited by Dr. Natalia Kamanina

ISBN 978-953-307-899-1

Hard cover, 210 pages

Publisher InTech

Published online 30, November, 2011

Published in print edition November, 2011

Following the targeted word direction of Opto- and Nanoelectronics, the field of science and technology related to the development of new display technology and organic materials based on liquid crystals ones is meeting the task of replacing volume inorganic electro-optical matrices and devices. An important way in this direction is the study of promising photorefractive materials, conducting coatings, alignment layers, as well as electric schemes that allow the control of liquid crystal mesophase with good advantage. This book includes advanced and revised contributions and covers theoretical modeling for optoelectronics and nonlinear optics, as well as includes experimental methods, new schemes, new approach and explanation which extends the display technology for laser, semiconductor device technology, medicine, biotechnology, etc. The advanced idea, approach, and information described here will be fruitful for the readers to find a sustainable solution in a fundamental study and in the industry.

\section{How to reference}

In order to correctly reference this scholarly work, feel free to copy and paste the following:

Yusuke Tsuda (2011). Polyimides Bearing Long-Chain Alkyl Groups and Their Application for Liquid Crystal Alignment Layer and Printed Electronics, Features of Liquid Crystal Display Materials and Processes, Dr. Natalia Kamanina (Ed.), ISBN: 978-953-307-899-1, InTech, Available from:

http://www.intechopen.com/books/features-of-liquid-crystal-display-materials-and-processes/polyimidesbearing-long-chain-alkyl-groups-and-their-application-for-liquid-crystal-alignment-layer-

\section{INTECH}

open science | open minds

\section{InTech Europe}

University Campus STeP Ri

Slavka Krautzeka 83/A

51000 Rijeka, Croatia

Phone: +385 (51) 770447

Fax: +385 (51) 686166

www.intechopen.com

\section{InTech China}

Unit 405, Office Block, Hotel Equatorial Shanghai

No.65, Yan An Road (West), Shanghai, 200040, China

中国上海市延安西路65号上海国际贵都大饭店办公楼405单元

Phone: +86-21-62489820

Fax: $+86-21-62489821$ 
(C) 2011 The Author(s). Licensee IntechOpen. This is an open access article distributed under the terms of the Creative Commons Attribution 3.0 License, which permits unrestricted use, distribution, and reproduction in any medium, provided the original work is properly cited. 